\title{
Sex expression and floral diversity in Jatropha curcas: A population study in its center of origin
}

María de Lourdes Adriano-Anaya, Edilma Pérez-Castillo, Miguel Salvador-Figueroa, Sonia Ruiz-González, Alfredo Vázquez-Ovando, Julieta Grajales-Conesa, Isidro Ovando-Medina

Sex expression and floral morphology studies are central to understand breeding behavior and to define the productive potential of plant genotypes. In particular, the new bioenergy crop Jatropha curcas L. has been classified as a monoecious species. Nonetheless, there is no information about its reproductive diversity in the Mesoamerican region, which is considered its center of origin and diversification. Thus, we determined sex expression and floral morphology in J. curcas populations from southern Mexico and Guatemala. Our results showed that most of J. curcas specimens had typical inflorescences separate sexes (monoecious), meanwhile the rest were atypical (gynoecious, androecious, andromonoecious, androgynomonoecious). The most important variables to group these populations, based on a discriminant analysis, were: male flower diameter, female petal length and male nectary length. From southern Mexico "Guerrero" was the most diverse population, and "Centro" had the highest variability among the populations from Chiapas. A cluster analysis showed that the accessions from southern Mexico were grouped without showing any correlation with the geographical origin, while those accessions with atypical sexuality were grouped together. To answer the question of how informative are floral morphological traits compared to molecular markers, we perform a Mantel correlation test between the distance matrix generated in this study and the genetic distance matrix (AFLP) previously reported for the same accessions. We found significant correlation between data at the level of accessions. Our results contribute to design genetic improvement programs by using sexually and morphologically contrasting plants from the center of origin. 
1 Sex expression and floral diversity in Jatropha curcas Linneo: A population study in its

2

3

4

5

6

7

8

9

10

11

12

13

14

15

16

17

18

19

20

21

22

23 center of origin

L. ADRIANO-ANAYA, E. PÉREZ-CASTILLO, M. SALVADOR-FIGUEROA, S. RUIZGONZALEZ, A. VÁZQUEZ-OVANDO, J. GRAJALES-CONESA, I. OVANDO-MEDINA*

Instituto de Biociencias, Universidad Autónoma de Chiapas. Boulevard Príncipe Akishino sin número, Col. Solidaridad 2000, Tapachula, 30798, Chiapas, Mexico.

*Corresponding author: fax (+52) 9626427972, e-mail: isidro.ovando@unach.mx 


\section{Abstract}

25 Sex expression and floral morphology studies are central to understand breeding behavior and to define the productive potential of plant genotypes. In particular, the new bioenergy crop

Jatropha curcas L. has been classified as a monoecious species. Nonetheless, there is no information about its reproductive diversity in the Mesoamerican region, which is considered its center of origin and diversification. Thus, we determined sex expression and floral morphology in J. curcas populations from southern Mexico and Guatemala. Our results showed that most of $J$. curcas specimens had typical inflorescences separate sexes (monoecious), meanwhile the rest were atypical (gynoecious, androecious, andromonoecious, androgynomonoecious). The most important variables to group these populations, based on a discriminant analysis, were: male flower diameter, female petal length and male nectary length. From southern Mexico "Guerrero" was the most diverse population, and "Centro" had the highest variability among the populations from Chiapas. A cluster analysis showed that the accessions from southern Mexico were grouped without showing any correlation with the geographical origin, while those accessions with atypical sexuality were grouped together. To answer the question of how informative are floral morphological traits compared to molecular markers, we perform a Mantel correlation test between the distance matrix generated in this study and the genetic distance matrix (AFLP) previously reported for the same accessions. We found significant correlation between data at the level of accessions. Our results contribute to design genetic improvement programs by using sexually and morphologically contrasting plants from the center of origin.

Keywords: breeding, Chiapas, flowering, Mexico, multivariate analysis 


\section{Introduction}

48 Jatropha curcas L. is a plant that has recently attracted interest as a scientific model and as an agro-industrial crop due to oil content of its seeds. However, knowledge of this plant's biology and ecology is still limited and recent studies locate the Mesoamerican region as its center of origin and diversity (Montes-Osorio et al. 2014).

Nonetheless, many studies about $J$. curcas have been performed with Asian and African accessions, where low genetic diversity is registered. Moreover, in the Mesoamerican region, particularly in Chiapas, Mexico there are few studies on genetic variation. Sánchez-Gutiérrez (2010) studied 147 accessions from five populations (Istmo, Frontera, Frailesca, Centro, and Soconusco) using AFLP markers; they found that the largest variation was within populations (94.2\%), while among populations the variation was $3.9 \%$, and the "Istmo" population was the most diverse. In other study, Pecina-Quintero et al. (2011) analyzed 88 accessions from seven regions in Chiapas by using AFLP markers; they found that one of the accessions (Tuxtla Chico) provided $100 \%$ of pistillate flowers (female) and showed the highest number of rare fragments. Recently, Montes-Osorio et al. (2014) analyzed the relationship between morphological traits and AFLP markers in populations from Central America compared to Africa, Asia and South America. Mesoamerican accessions registered the highest phenotypic and molecular variation. These results are being used to identify QTL markers that contribute to improve agronomic performance for seed and oil productivity (King et al. 2015). Thus, the use of molecular markers and morphological traits may be useful to differentiate populations. Heller (1996) described $J$. curcas morphological traits, and found size changes in canopy, stem, root, bark and leaves. These variations on morphological traits are being observed in Indian landraces, on seed allometry (Ginwal et al. 2005) and morpho-physiological variation (Saikia et al. 2009). The 
70 parameters evaluated by Saikia et al. (2009) were plant height, stem girth, branches per plant and

71100 seed weight. Nonetheless, there is a lack of information about inflorescences and flowers

72 traits, which are considered highly conserved and could be used as estimators of J. curcas

73 genetic diversity in Mesoamerica. In Chinese accessions (Wu et al. 2011), floral phenology was

74 divided into twelve phases, where sexual differentiation in male and female flowers occurs in the

75 seventh phase, besides that some plants possess mainly male and female flowers. To our

76 knowledge, no sexual types and floral traits research exists in the center of origin. Therefore, this

77 study aimed a) to describe $J$. curcas sex diversity; b) to assess the variability in Mesoamerican

78 accessions with floral markers; and c) to analyze the relationship between floral traits and

79 molecular markers.

81 Materials and methods

82 Biological material and study site

83 We studied $103 \mathrm{~J}$. curcas accessions (Table S1), collected in 33 sites in southern México

84 (Ovando-Medina et al. 2011a). Three years old plants were grown without any agronomic 85 management in Jatropha Germplasm Bank of the Universidad Autónoma de Chiapas (Mexico)

$86\left(14.4976 \mathrm{~N}, 92.4774 \mathrm{~W}\right.$ and 58 meters above sea level; average annual temperature of $31^{\circ} \mathrm{C}$,

87 average annual humidity $80 \%$, average of $2600 \mathrm{~mm}$ of rainfall and soil type andosol). From each

88 accession, male flowers $(n=40)$ and female flowers $(n=20)$ were collected. Flowers were

89 transported to the laboratory in polybags and stored at $4^{\circ} \mathrm{C}$ for up to 48 hours.

90 Classification of flowers

91 The number of inflorescences was determined every 28 days during a year. Flowers were

92 classified as female, male and hermaphrodite; first the pedicel was removed from each of the 
93 flowers and then photomicrographs were taken by using a compound microscope (Zeiss

94 Axiolab®) and / or stereoscope (Zeiss Stemi $2000 \mathrm{C} \circledast$ ) equipped with a video camera (AxioCam

$95 \mathrm{MRc}()$ ) coupled to the Axio Vision (C) program.

96 Floral traits

97 For all the flowers we determined the number of sepals, petals and nectaries. For male and

98 hermaphrodite flowers the number of filaments, anthers and pollen count was determined. For

99 female and hermaphrodite flowers the number of ovules and the size of the pistil and ovary were

100 determined. We also measured the length and/or width and/or diameter and/or thickness of floral

101 character. The presence of trichomes was evaluated according to the following scale: glabrous,

102 moderately pubescent and abundantly pubescent flowers.

103 Statistical Analysis

104 In order to minimize differences observed in traits, our data were coded as shown in Table S2.

105 These data were processed by a multivariate discriminant analysis, where the most informative

106 characters were identified and populations were grouped. Then, a cluster analysis (Euclidean

107 distance and Ward grouping method) was performed to visualize the relationships among

108 populations. In both analyses two approaches were followed: one with all populations and the

109 second one only with Chiapas populations (the most numerous). All statistical analyses were

110 performed with the XLStatC v 2014 and InfoStatC v 2014 software. In addition, to answer the

111 question of how informative are floral morphological traits compared to molecular markers, a

112 Mantel correlation test was performed using GenAlEx $\subset$ version 6.3 program. This correlation

113 was carried out between data reported by Sánchez-Gutiérrez (2010) and the matrix of Fisher's

114 distances obtained in this discriminant analysis. This procedure was done with five populations

115 and 87 accessions. 


\section{Results and discussion}

\section{Flowering dynamics}

119 In our results, flowers were observed throughout the year only in four accessions (ARR-7, 120 CDCU-3, MAP-8 and PC-15). The rest blossomed from one to three times a year; $85.2 \%$ 121 flowered from March to April, while in $59 \%$ flowered during August and only $40.1 \%$ of the 122 accessions flowered at the start of November (Figure S1).

123 Many factors affect the start of flowering, like genetic variability, nutrients, phyto-hormones and 124 environmental conditions. Soil humidity may be involved in triggering flower formation because 125 we observed a clear relationship between the beginning of rainy season and $J$. curcas flowering 126 (Figure S2). Control of soil humidity could be key to induce continuous blooming, as suggested 127 by Sukarin et al. (1987). Geographic location influences the period, intensity and frequency of 128 rain, thus flowering peak changes, e.g. in Nicaragua this was observed during April, May, June 129 and August (Aker 2012) and in India from July to September (Sukarin et al. 1987, Bhattacharya 130 and Kumar 2005).

131 J. curcas has terminal inflorescences (Halle et al. 1978), so the number of them in the plant 132 depends on the number of mature branches (terminal sprouts) present at the time of sampling. 133 From our results, the genetic determinant of flowering in $J$. curcas accessions used in this study 134 seems a highly influential factor, since the number of inflorescences per plant was accession135 specific.

136 Sex offlowers in J. curcas accessions

137 We found female, male and hermaphrodite flowers in the study accessions (Figure 1), and based 138 on the proportion of each flower sex, plants were classified as gynoecious, androecious, 
139 andromonoecious, androgynomonoecious (Table 1). Dehgan and Webster (1979) reported that $J$.

140 curcas is known as a monoecious plant (male and female flowers on the same inflorescence, also

141 with hermaphrodite ones), without specifying if this is a genotype-specific characteristic. Some

142 other studies reported plants with only female flowers (Pecina-Quintero et al. 2011) or

143 predominantly with male flowers (Wu et al. 2011).

144 The presence of dioecism and complex arrangements, and the fact that most individuals were 145 monoecious indicate that in this plant sex is linked to a complex determinant. Probably J. curcas 146 had sex chromosomes like to other species with similar sex expression (Charlesworth, 2016). 147 Dioecism, in plants, is related to various ecological factors (Vamosi et al. 2009) and is observed 148 in several groups of unrelated plants. The appearance of dioecism has been reported in the genus 149 Ribers (Senters and Solis 2003) and has appeared at least twice in the genus Silene from a 150 gynodioecious ancestor (Desfeux et al. 1996). In particular, in the Siparunaceae family, dioecism 151 was originated from a monoecious ancestor (Renner and Won 2001). In monocots the dioecious 152 nature seems to have evolved from a transient gynodioecious state more than the monoecious 153 state (Weiblen et al., 2000). The existence of complex systems has been documented in 154 dioecious crops as apple (Hancock, 2012) and hemp (Mandolino et al., 1999).

155 In contrast to animals, the sexual dimorphism appearance in angiosperms was not associated 156 with the evolution of sex chromosomes, with exception of a few species (Ruiz 2004). 157 Heteromorphic sex chromosomes are widely distributed in higher animals but in contrast to the 158 study of the origin and evolution of X and Y chromosomes in humans (Skaletsky et al. 2003), 159 plants sex chromosomes have been scarcely studied. It is estimated that animals sex 160 chromosomes appeared 240 to 320 million years ago (Charlesworth 2002). Therefore, younger 161 systems like dicots (Ruiz 2004) are interesting to prove this hypothesis. Although sexual 
162 determinism in plants and animals is fundamentally different, the architecture of sex

163 chromosomes is likely to be comparable (Charlesworth 2002). It has been hypothesized that sex

164 chromosomes evolved from autosomes and have required at least two evolutionary events for the

165 transition from hermaphroditism to dioecism (Charlesworth 1991). Therefore, a male sterility

166 mutation in hermaphrodites (gynomonoecious) would give way to females, and then the males

167 would appear from the suppression of female genes. However, in this study with J. curcas

168 collected in its center of origin and diversity (Salvador Figueroa et al. 2015, Pamidimarri and

169 Reddy 2014) we did not find gynomonoecious individuals, which could be possible by a) $J$.

170 curcas gynoecious plants originated by one mutational step from a hermaphrodite ancestor, or b)

171 the gynodioecia emerged from androgynomonoecious populations (Figure 2). Therefore, it is

172 necessary to perform a study involving more individuals to confirm the absence of

173 gynomonoecious. Reminiscences of sex chromosomes could be found in androgynomonoecious

174 and andromonoecious individuals.

175 Variation of J. curcas floral characters

176 We observed casual and recurrent variations in J. curcas floral traits. The first type refers to the

177 variability among inflorescences of the same plant, which may have the origin in the genotype-

178 environment interaction (Heller 1996) or in epigenetic factors (Yi et al. 2010). Examples of

179 occasional variation in male flowers are: number of petals (four or five), sepals (four, five or

180 six), nectaries (four or five) and stamens (seven to ten). In female flowers occasional variation

181 was found in the number of ovules (two, three or four). The second type of variation refers to

182 features that were always present in the same plant, such as the amount of trichomes and the size

183 of the characters. It is possible that the characters had recurrent variation, whether fixed or highly 
184 heritable (Ovando-Medina et al. 2011a). Only the recurrent variation was used for studies of 185 diversity on $J$. curcas populations from southern México.

186 Our results revealed that the typical male flowers whorls (Figure 1A) were composed of five 187 petals, five sepals, five nectaries, ten stamens, ten anthers and pollen grains (27-44 $\mu$ m diameter), 188 and female flowers (Figure 1B); five petals, five sepals, five nectaries, one ovary, three ovules, 189 one pistil. In hermaphrodite flowers (Figure 1C) there are five petals, five sepals, five nectaries, 190 ten stamens, pollen grains ranging from 37-40 $\mu \mathrm{m}$ in diameter, one ovary, three ovules, one 191 pistil. These data agree with those previously reported by other authors (Heller 1996, Toral et al. 192 2008, Wu et al. 2010).

193 Regarding flowers size, we found that male flowers are smaller $(5-10 \mathrm{~mm})$ than female (7-15 $194 \mathrm{~mm})$ and hermaphrodites (11-14 mm) ones; they also have a light green-yellow color, with most 195 of flowers moderately pubescent. In contrast, Toral et al. (2008) mentioned that male and female 196 flowers are small (6-8 mm), have a greenish-yellow color, with some pubescent flowers, and 197 with versatile anthers and protruding sexual organs.

198 We also observed two hermaphrodite flower types; one with ten stamens around the ovary longer 199 than the pistil and the second one with four to six stamens around the ovary shorter than the 200 pistil. The first type could be considered as a strategy to be self-fertilized, because the pollen sac 201 opens, and this can be used by the receptive stigma, without needing a dispersing agent 202 (Ocampo-Velázquez et al. 2009). Pinilla et al. (2011) observed that J. curcas hermaphrodite 203 flowers exhibit protrandy, since the development of the male and female phases first release 204 pollen by manifesting as gynoecium growth in style and stigma, once produced senescence in the 205 anthers, styles reach their ideal size when the papillae are already developed. 
207 For the first discriminant analysis we used all populations from Southern Mexico, and the most 208 important characters were identified to form the five principal components and to group 209 accessions by populations. Principal component $1\left(\mathrm{Cl}_{\mathrm{A}}\right)$ was the most important accounting for $21046.02 \%$ of the total variation (Table 2) and the most important variables for their contribution to $211 \mathrm{Cl}_{\mathrm{A}}$ were: male flower diameter (MFD), female sepal length (FSL), female petal length (FPL), 212 female flower diameter (FFD) and pistil thickness (PT) (Table S3). Principal component $2\left(\mathrm{C} 2_{\mathrm{A}}\right)$ 213 accounted for $20.90 \%$ of the variance (Table 2) and the variables that contributed most to this 214 factor were: pistil thickness (PT), ovary lenght (OL), male nectary length (MNL) and female 215 nectary length (FNL). The variables correlated to the main component 3 (F3) were ovule lenght 216 (OL), quantity of trichomes in female flowers (TF) (Table S3), with 13.64\% of the variance, 217 whereas the main component 4 and 5 only explained $5-8 \%$ of the total variation as shown in 218 Table 2.

219 Many authors have performed studies on $J$. curcas morphological variation by using principal 220 component analysis, e.g. Zapico et al. (2011) in the Philippines evaluated 21 quantitative 221 morphological variables for 13 accessions of $J$. curcas, the five principal components accounted 222 for $88.12 \%$ of the total variation, where the most important variables for the principal component 2231 were: plant height, number of leaves, percentage of seed germination and survival. Moreover, 224 Vijayanand et al. (2009), studied 12 accessions of $J$. curcas to assess genetic diversity using 19 225 morphological characters, finding that the first three factors contributed $89.2 \%$ of the total 226 observed variance, the variables that contributed most to the component 1 were: stem diameter, 227 length and width of the leaf, and plant growth, which contributed $35.7 \%$. Machado (2011) 228 conducted a study to characterize the morphological and productive variability of a collection of $229 J$. curcas in Cuba, taking into account 13 morphological characters, finding that plant height was 
230 the most variable indicator, followed by the thickness of stem and primary branches, number of

231 primary and secondary branches, accounting for $74.63 \%$ between the principal component 1 and

232 principal component 2 . However, there have been no previous investigations on floral variation

233 found in J. curcas for possible comparison.

234 We observed that the grouping pattern of accessions by population, according to $\mathrm{C} 1_{\mathrm{A}}$ and $\mathrm{C} 2_{\mathrm{A}}$,

235 accounted for $66.92 \%$ of the variance shown (Figure 3), where accessions belonging to Frontera

236 and Oaxaca populations were grouped into $\mathrm{C} 1_{\mathrm{A}}$, while accessions belonging to the Istmo and

237 Centro populations in the $\mathrm{C} 2{ }_{\mathrm{A}}$. Guerrero's position in the lower left quadrant is due to the high 238 percentage of variance shown by these accessions in the evaluated characters and their 239 contribution to the $\mathrm{Cl}_{\mathrm{A}}$ and $\mathrm{C} 22_{\mathrm{A}}$. These results are probably due to existing plants in this 240 population with hermaphrodite flowers (see arrows in Figure 3).

241 The relationship between populations and centroids were plotted in Figure 4, in order to show

242 how Centro and Istmo populations are closely related since Istmo is found within the centroid of

243 Centro population. Also, this population is related to the populations of Oaxaca and Frailesca,

244 which may be due to the geographical proximity between them. Meanwhile, populations of

245 Guatemala, Frontera, Soconusco and Guerrero were separated from the rest and between

246 themselves. It is remarkable how different are the Frontera and Soconusco populations, even

247 though they are geographically closed, this may be due to the physical barrier represented by the

248 Sierra Madre de Chiapas. Moreover, Guerrero was the most diverse population, probably

249 because there are plants with hermaphrodite flowers in this population.

250 Ovando-Medina et al. (2011a), used the same accessions and studied the genetic diversity

251 estimated with fatty acids of $J$. curcas seeds, they reported that the variation with respect to oil

252 content was $8.020 \%-54.28 \%$. They also found that the two principal components together 
253 explained $89.25 \%$ of the total variation. By a graph of centroids the relationship between the six

254 populations was shown; the results were similar to the observed by grouping based on floral

255 characters variation, as Guatemala was one of the most diverse populations in both studies, in

256 addition to the close relationship in which the populations of the center and coast of Chiapas

257 were grouped.

258

259 We also carried out a second discriminant analysis, which exclusively studied accessions from

260 Chiapas, because in that State there is the greatest extension of traditional cultivation of J. curcas

261 in Mexico. The major characters were identified to form the five principal components and

262 grouped the accessions by populations. The most important component $\left(\mathrm{C} 1_{\mathrm{B}}\right)$ explained $58.40 \%$

263 of the total variation (Table 3) and its most informative variables were diameter of the male

264 flower (DMF), length of male sepal (LMS), male petal width (APM) and female petal length

265 (LPF). Principal component $2\left(\mathrm{C} 2_{\mathrm{B}}\right)$ accounted for $20.92 \%$ of the variance (Table 3$)$ and the

266 most important variables were length of male nectary (LNM), width of the male anther (AAM),

267 length of the ovule (LOvu) and the amount of trichomes on female flowers (TF). For $\mathrm{C} 3_{\mathrm{B}}$ the

268 most important variables were: the number of trichomes on male flowers (TM) and length of

269 ovary (LO) accounting for a $16.81 \%$ variance, while the $\mathrm{C}_{\mathrm{B}}$ contributed less variation than $4 \%$

270 of the total variance, as shown in Table 3. Contributions of studied traits to construct the

271 principal components are showed in Table S4.

272 Considering the two discriminant analyses, the most important variables for all populations were

273 the diameter of the male flower (DFM), female petal length (LPF), length of male nectary, male

274 flower diameter (DFM), female petal length (LPF) and length of male nectary (LNM). 
275 Pinilla et al. (2011), studied 246 accessions of J. curcas from Colombia through the study of 24

276 qualitative and quantitative morphological characters, finding that plant height, stem diameter,

277 canopy projection, length and width of the eighth leaf, days flowering, weight and fruit length,

278 length and width of the seed, explained a $93.62 \%$ of the variance.

279 In Figure 5, the grouping pattern of accessions per population, according to $\mathrm{C} 1_{\mathrm{B}}$ and $\mathrm{C} 2_{\mathrm{B}}$, which

280 together account for $79.31 \%$ of the variance, shows how accessions belonging to the population

281 Soconusco is the only group around $\mathrm{C}_{\mathrm{B}}$, while populations of Istmo and Centro are grouped at $282 \mathrm{C} 2_{\mathrm{B}}$.

283 The relationships between the five populations may be visualized when the centroids (Figure 6)

284 are plotted, where we observed a group containing the Istmo, Frailesca and Centro populations.

285 Frontera and Soconusco populations showed a marked differentiation between them and with

286 respect to other populations. This shows that the Sierra Madre de Chiapas is a strong physical

287 barrier between these populations and may be the main cause of diversification among

288 populations. Centro was the most diverse population.

289 Cluster analysis of morphological characters of flowers

290 Two analyses of hierarchical ascendant classification (dendrogram or cluster analysis) were

291 undertaken: one of them analyzed 103 accessions from southern México, finding a dendrogram

292 with five groups as shown in Figure 7. The first group was the largest and contained 54

293 accessions from most populations, showing no correlation with geographical origin. The second

294 group only gathered eight accessions, the majority from the population of Istmo. The third group

295 consists of 35 accessions, which belongs to Centro, Frontera, Soconusco, Guatemala and

296 Veracruz populations. The fourth group consists of ginoecious plants i.e. that only produce

297 female flowers. The last group was formed from two androecious accessions (plants), i.e. that 
298 only produce male flowers, and one andromonoecious plant, i.e. producing hermaphrodite and

299 male flowers. There was no group according to geographical origin. The percentage of variation

300 within groups was $59.43 \%$, while between groups was $40.57 \%$, which means that larger variance

301 is within groups.

302 In the second analysis of hierarchical ascendant classification (dendrogram or cluster analysis)

30390 accessions from the Chiapas state were studied and our results showed five groups (Figure 8).

304 The first group was the second largest consisting of 38 accessions, also from all populations

305 (Soconusco, Frontera, Istmo and Centro), but most were from Soconusco populations, while in

306 the second group eight accessions were included, most from the Istmo population. The third

307 group was the largest and consisted of 39 accessions of all populations. The fourth group was

308 formed by two accessions; these plants were androecious, i.e. only produce male flowers.

309 Finally, the last group consists of three gynoecious plants, i.e. accessions with only female

310 flowers. Groups showed no correlation according to their geographical origin. The percentage of

311 variation within groups was $57.55 \%$, while between groups was $42.45 \%$, meaning that the

312 existing variance is greatest within groups.

313 The results coincide with those found by Sánchez-Gutiérrez (2010), who used the same

314 accessions to study genetic variation in J. curcas in the state of Chiapas. The author found using

315 cluster analysis, that the accessions are grouped without a geographical pattern.

316 The Mantel test results showed that matrices generated by populations are not correlated $(p=$

317 0.448), while the matrices generated by accessions did show correlation $(p=0.001)$. This means

318 that the study of the diversity of $J$. curcas using floral morphological markers reveals grouping

319 patterns in accessions similar to those obtained with AFLP molecular markers. 
320 Although there are many studies of $J$. curcas diversity collected in different regions of the world

321 (for a review see Ovando-Medina et al. 2011b), no reports use floral markers as estimators of

322 variation, so we were unable to compare the findings of this study. A characterization study of

323 floral development in J. curcas was reported by Wu et al. (2011), who discussed in detail the

324 anatomy of flowers and inflorescences, but did not present data on variation between accessions.

325 Our results contribute to $J$. curcas sex expression knowledge from the living fences in southern

326 México, which indicated, together with data from other research using phenotypic and molecular

327 markers, that the Mesoamerican region is a center of diversification for this species.

328

\section{Conclusions}

330 Jatropha curcas L. floral traits in the Mesoamerican region are highly variable between 331 accessions. Our results showed that male flower diameter, female petal length, male nectary 332 length are the most informative. Even though $93.2 \%$ of the accessions were monoecious, the rest 333 of them were androecious, gynoecious, andromonoecious or androgynomonoecious.

334 Despite their geographical proximity, the Frontera and Soconusco populations are differentiated 335 in their floral characters.

336 The multivariate analysis registered that $J$. curcas accessions from southern México were 337 grouped without a geographic pattern, while accessions with atypical sexuality were grouped 338 together; in this way, one group was formed by gynoecious plants and another by androecious 339 and andromonoecious accessions.

\section{References}


343 Aker C.: [The reproductive biology of Jatropha curcas]. Centro de Investigación Forestal,

344 Facultad de Ciencias y Tecnología Universidad Nacional Autónoma de Nicaragua, León.

345 Conference proceedings. 2012. [In Spanish]

346 Bhattacharya, A., Kumar, S.: Floral biology, floral resource constraints and pollination limitation

347 in Jatropha curcas L. - Pakistan J. Biol. Sci. 8: 456-460, 2005.

348 Charlesworth, D. Plant sex chromosomes. Annual Review of plant Biology first online. DOI:

349 10.1146/annurev-arplant- 043015-111911. 2016.

350 Charlesworth, D.: Plant sex determination and sex chromosomes. - Heredity 88: 94-101, 2002.

351 Charlesworth, B.: The evolution of sex chromosomes. - Science 251: 1030-1033, 1991.

352 Dehgan, B., Webster, G.: Morphology and infrageneric relationships of the genus Jatropha

353 (Euphorbiaceae). - U. Calif. Publ. Bot. 74: 1-73, 1979.

354 Desfeux, C., Maurice, S., Henry, J., Lejeune, B., Gouyon, P.: Evolution of reproductive systems

355 in the genus Silene. - Proc. R. Soc. Lond. B. 263: 409-414, 1996.

356 Ginwal, H.S., Phartyal, S.S., Rawat, P.S., Srivastava, R.L.: Seed source variation in morphology, germination and seedling growth of Jatropha curcas Linn. in Central India. - Silvae Genet. 54: 76-80, 2005.

Halle, F., Oldeman R., Tomlinson, P.: Tropical trees and forests. An architectural analysis. Springer Verlag, Berlin-Heidelberg-New York, 1978.

Hancock JF. 2012. Plant evolution and the origin of crop species. Third edition. Wallingford, UK: CABI. pp. 245.

Heller, J.: Physic nut. Jatropha curcas L. Promoting the conservation and use of underutilized and neglected crops. Institute of Plant Genetics and Crop Plant Research Gatersleben Germany, / International Plant Genetic Resources Institute Rome, Italy, 1996. 
366 King AJ, Montes LR, Clarke JG, Itzep J, Perez CA, Jongschaap RE, Visser RG, van Loo EN,

367

368

369

370

371

372

373

374

375

376

377

378

379

380

381

382

383

384

385

386

387
Graham IA. 2015. Identification of QTL markers contributing to plant growth, oil yield and fatty acid composition in the oilseed crop Jatropha curcas L. Biotechnol Biofuels 8:160..

Machado, R.: [Morphological and productive characterization of provenances of Jatropha curcas L]. - Pastos y Forrajes 34: 267-280, 2011. [In Spanish]

Mandolino G, Carboni A, Forapani S, Faeti V, Ranalli P. Identification of DNA markers linked to the male sex in dioecious hemp (Cannabis sativa L.). Theoretical and Applied Genetics 98: 86-92, 1999.

Osorio, L. R. M., Salvador, A. F. T., Jongschaap, R. E. E., Perez, C. A. A., Sandoval, J. E. B., Trindade, L. M., ... \& van Loo, E. N. (2014). High level of molecular and phenotypic biodiversity in Jatropha curcas from Central America compared to Africa, Asia and South America. BMC plant biology, 14(1), 1.

Ocampo-Velázquez, R., Malda-Barrera, G., Suárez-Ramos, G.: [Reproductive biology of Mexican oregano (Lippia graveolens Kunth) in three conditions of use]. - Agrociencia 43: 475-482, 2009. [In Spanish]

Ovando-Medina, I., Espinosa-García, F.J., Núñez-Farfán, J., Salvador-Figueroa, M.: Genetic variation in Mexican Jatropha curcas L. estimated with seed oil fatty acids. - J. Oleo Sci. 60: $301-311,2011 \mathrm{a}$.

Ovando-Medina, I., Espinosa-García, F. J., Núñez-Farfán, J. S., Salvador-Figueroa, M.: State of the art of genetic diversity research in Jatropha curcas. - Sci. Res. Essays 6: 1709-1719, $2011 b$. 
388 Pamidimarri, D.V.N.S., Reddy, M.: Phylogeography and molecular diversity analysis of

389 Jatropha curcas L. and the dispersal route revealed by RAPD, AFLP and nrDNA-ITS

390 analysis. - Mol. Biol. Rep. 41: 3225-3234, 2014.

391

392

393

394

395

396

397

398

399

400

401

402

403

404

405

406

407

408

409

410

Pecina-Quintero, V., Anaya-López, J.L., Zamarripa, A., Montes, N., Nuñez, C.A., Solis, J.L., Aguilar-Rangel, M.R., Gill, H.R., Mejía, D.J.: Molecular characterisation of Jatropha curcas L. genetic resources from Chiapas, México through AFLP markers. - Biomass Bioenerg. 35: 1897-1905, 2011.

Pinilla, J.A., Campusano, L.F., Rojas, S., Pachon-García, J.: [Morphological and agronomical characterization of Jatropha curcas L. from National Germplasm Collection]. - Orinoquia 15: 131-147, 2011. [In Spanish]

Renner, S., Won, H.: Repeated evolution of dioecy from monoecy in Siparuna (Siparunaceae, Laurales). - Syst. Biol. 50: 700-712, 2001.

Ruiz, M.: Sex chromosomes in plants. - In Goodman R. (ed.): Encyclopedia of plant and crop science. Vol. 4. Pp. 1148-1151. Dekker Agropedie. Marcel Dekker - New York 2004.

Saikia, S.P., Bhau, B.S., Rabha, A., Dutta, S.P., Choudhari, P.K., Chetia, M., Mishra B.P.; Kanjilla P.B.: Study of accession source variation in morpho-physiological parameters and growth performance of Jatropha curcas Linn. - Curr. Sci. 96: 12-25, 2009.

Sánchez-Gutiérrez, A.: [Population genetic diversity of Jatropha curcas L. from state of Chiapas, Mexico]. Bachelor thesis. Centro de Biociencias, Universidad Autónoma de Chiapas, Mexico. 18 pp., 2010. [In Spanish]

Salvador-Figueroa, M., Magaña-Ramos, J., Vázquez-Ovando, J.A., Adriano-Anaya, M. L. Ovando-Medina. I.: Genetic diversity and structure of Jatropha curcas L. in its centre of origin. - Plant Genet. Resour. 13: 9-17, 2015. 
411 Senters, A., Solis, D.: Phylogenetic relationship in Ribes (Glossulariaceae) inferred from ITS 412 sequence data. - Taxon 52: 51-66, 2003.

413

414

415

416

417

418

419

420

421

422

423

424

425

426

427

428

429

430

431

432

Skaletsky, H., Kuroda-Kawaguchi, T., Minx, P., Cordum, H., Hillier, L., Brown, L., Repping, S., Pyntikova, T., Ali, J., Bieri, T., Chinwalla, A., Delehaunty, A., Delehaunty, K., Du, H., Fewell, G., Fulton, L., Fulton, R., Graves, T., Hou, S., Latrielle, P., Leonard, S., Mardis, E., Maupin, R., McPherson, J., Miner, T., Nash, W., Nguyen, C., Ozersky, P., Pepin, K., Rock, S., Rohlfing, T., Scott, K., Schultz, B., Strong, C., Tin-Wollam, A., Yang, S., Waterston, R., Wilson, R., Rozen, S., Page, D.: The male-specific region of the human Y chromosome is a mosaic of discrete sequence clases. - Nature 423: 825-837, 2003.

Sukarin W., Yamada Y., Sakaguchi S.: Characteristics of physic nut, Jatropha curcas L. As a new biomass crop in the tropics. - Japan. Agric. Res. Quart. 20: 302-303, 1987.

Toral, O., Iglesias, J.M., Montes, S., Sotolongo, J.A., García. S., Torsti, M.: [Jatropha curcas L., a tree species with energy potential in Cuba]. - Pastos y Forrajes 31:191-207, 2008. [In Spanish]

Vamosi, S., Heard, S., Vamosi, J., Webb, C.: Emerging patterns in the comparative analysis of phylogenetic community structure. - Mol. Ecol. 18: 572-592, 2009.

Vijayanand, V., Senthil, N., Vellaikumar, S., Paramathma, M.: Genetic diversity of Indian Jatropha species as revealed by morphological and ISSR markers. - J. Crop. Sci. Biotech. 12: 115-120, 2009.

Weiblen, G.D., Oyama, R.K., Donoghue, M.J.: Phylogenetic analysis of dioecy on monocotylendons. - Am. Nat. 155: 46-58, 2000.

Whitaker, T.W., Davis, G.N. Cucurbits. Botany, cultivation, and utilization. Hill-London, 1962. 
433 Wu, J.L.Y., Tang, L., Zhang, F., Chen, F.: A study on structural features in early flower 434 development of Jatropha curcas L. and the classification of its inflorescences. - Afr. J. $435 \quad$ Agric. Res. 6: 275-284, 2011.

436 Yi, C., Zhang, S., Liu, X., Bui, T.H., Hong, Y.: Does epigenetic polymorphism contribute to 437 phenotypic variances in Jatropha curcas L.? - BMC Plant Biol. 10: 259, 2010.

438 Zapico, F.L., Nival, S.K., Aguilar, C.H., Eroy, M.N.: Phenotypic diversity of Jatropha curcas L. 439 from diverse origins. - J. Agric. Sci. Technol. 5: 215-219, 2011. 
Figure 1 (on next page)

Types of Jatropha curcas flowers.

Differentiation of Jatropha curcas flowers according to sex, male flower (a), female flower (b), hermaphroditic flower (c). 


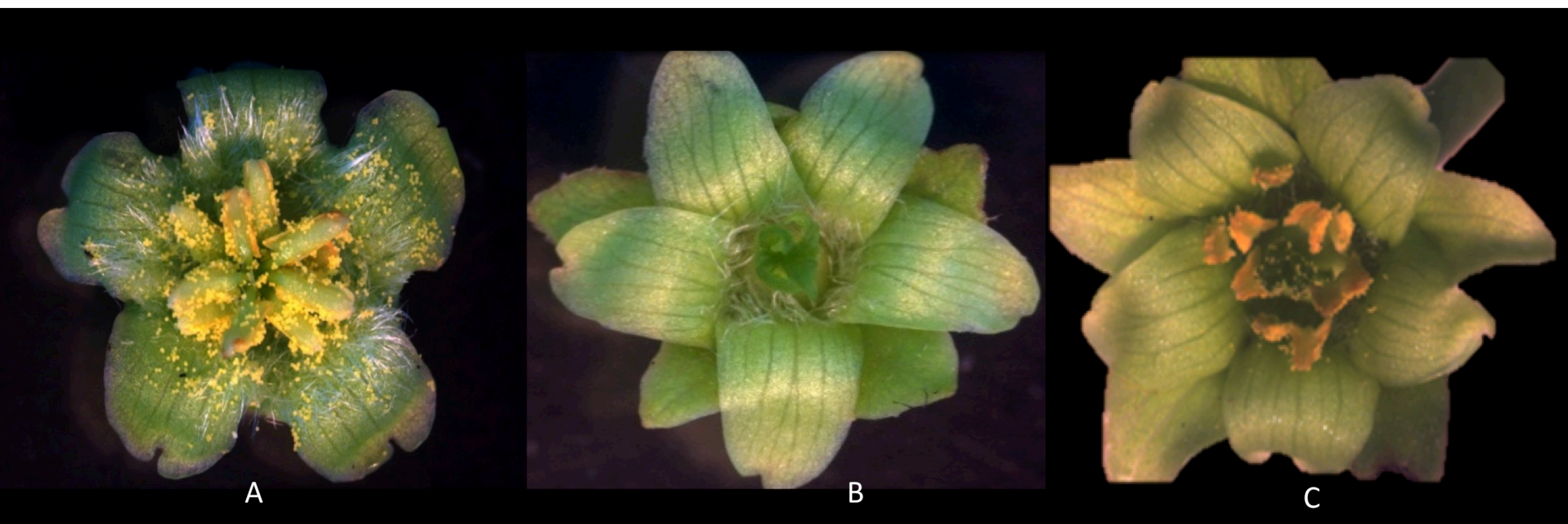


2

Sex expression in the biofuel plant Jatropha curcas.

Phylogenetic hypothesis of the evolution of sexuality in the tropical tree Jatropha curcas L. (Euphorbiaceae).

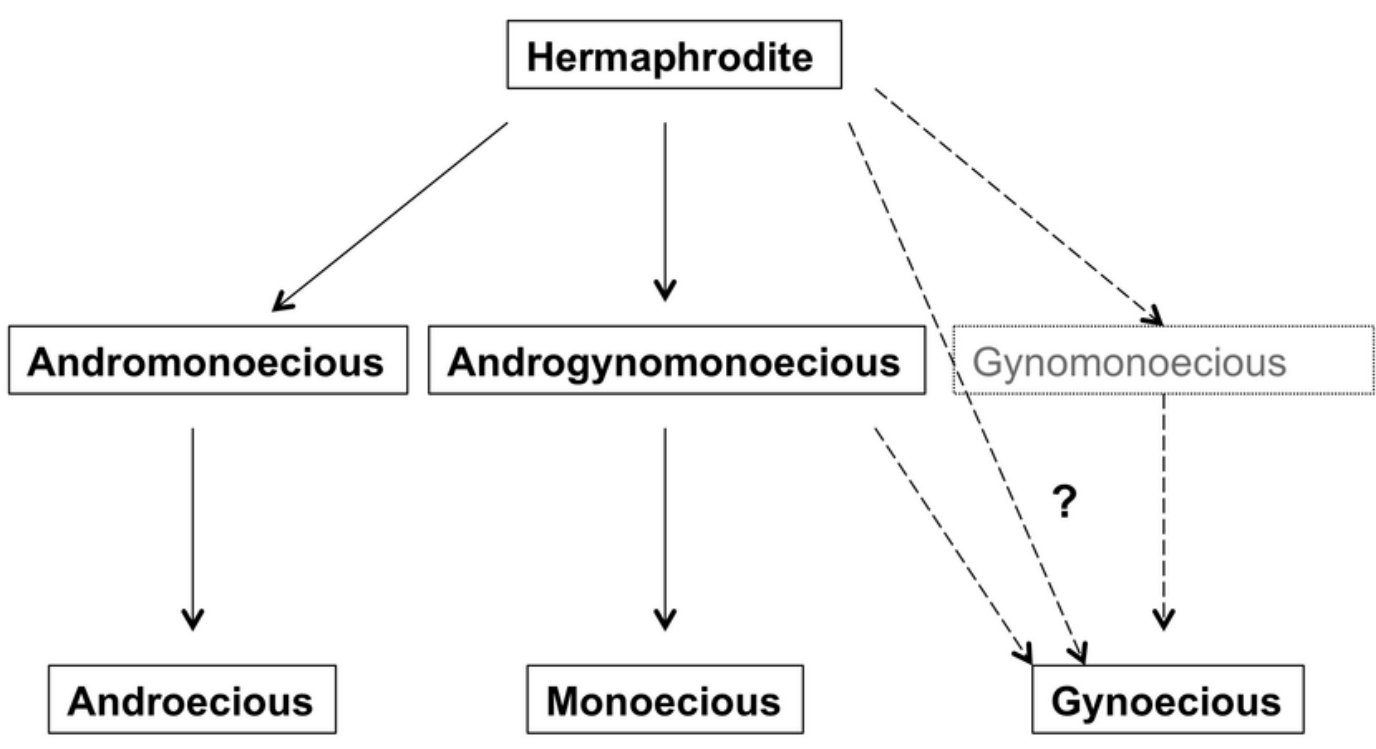

Plesiomorphic state

Intermediate state

Modern state 


\section{3}

Discriminant analysis of landraces of Jatropha curcas from Meso-America.

Groupings by populations of 103 accessions of Jatropha curcas L. of southern México, from the Jatropha Germplasm Bank of the Autonomous University of Chiapas. Traits: Male flower diameter, Male sepal lenght, Male sepal width, Male petal lenght, Male petal width, Male nectary length, Male nectary thickness, Filament lenght, Filament thickness, Anther lenght, Anther thickness, Pollen diameter, Trichomes in male flowers, Female/hermaphrodite flower diameter, Female/hermaphrodite sepal length, Female/hermaphrodite sepal width, Female/hermaphrodite petal length, Female/hermaphrodite petale width, Female/hermaphrodite nectary length Female/hermaphrodite nectary thickness, Pistil lenght, Pistil thickness, Ovary lenght, Ovary thickness, Ovule lenght, Ovule thickness, Trichomes in female/hermaphrodite flowers. 


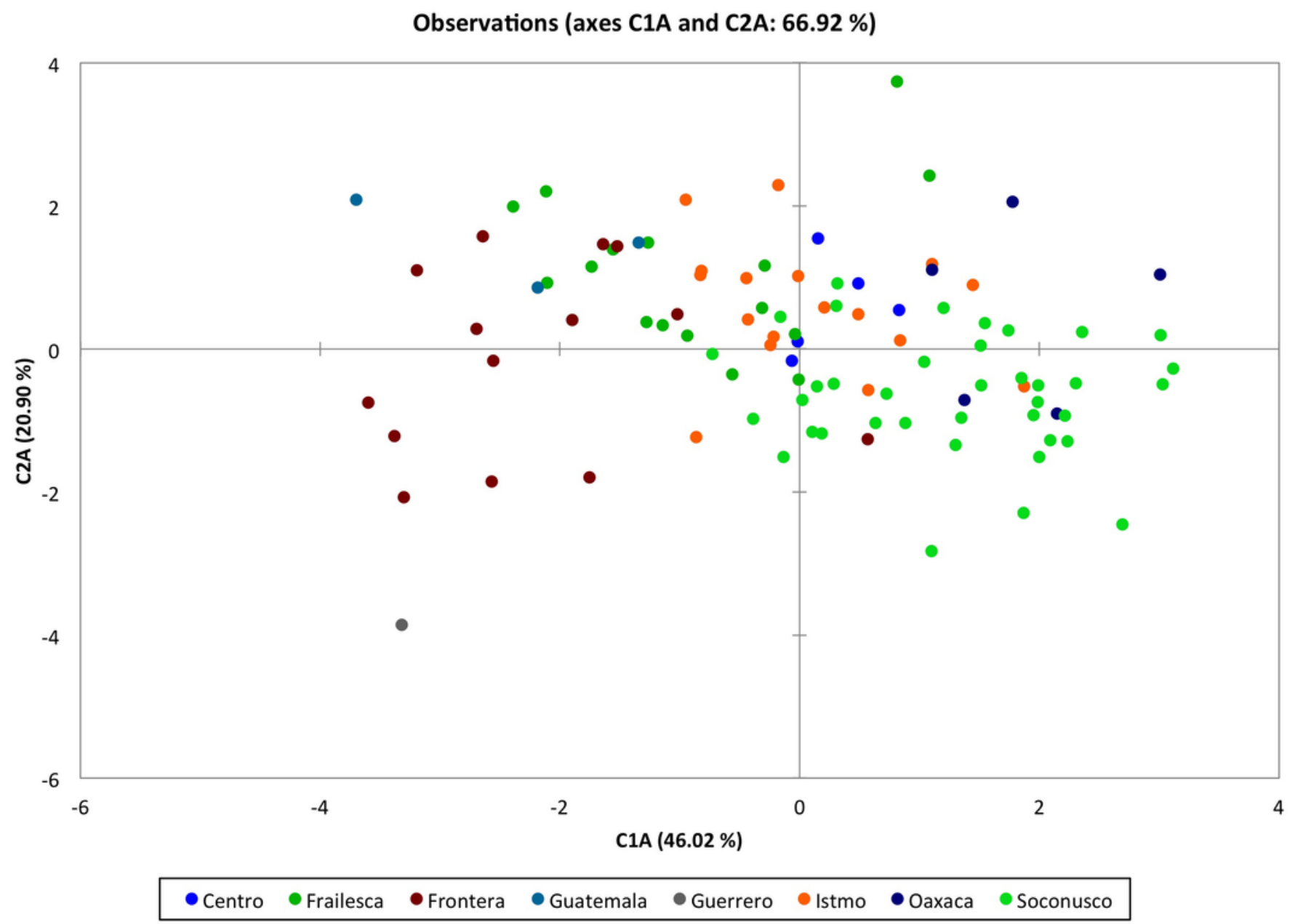




\section{4}

Grouping of Jatropha curcas landraces based on discriminant analysis.

Graph of centroids of the eight populations of Jatropha curcas L. in southern México, from the Jatropha Germplasm Bank of the Autonomous University of Chiapas. Traits: Male flower diameter, Male sepal lenght, Male sepal width, Male petal lenght, Male petal width, Male nectary length, Male nectary thickness, Filament lenght, Filament thickness, Anther lenght, Anther thickness, Pollen diameter, Trichomes in male flowers, Female/hermaphrodite flower diameter, Female/hermaphrodite sepal length, Female/hermaphrodite sepal width, Female/hermaphrodite petal length, Female/hermaphrodite petale width, Female/hermaphrodite nectary length Female/hermaphrodite nectary thickness, Pistil lenght, Pistil thickness, Ovary lenght, Ovary thickness, Ovule lenght, Ovule thickness, Trichomes in female/hermaphrodite flowers. 


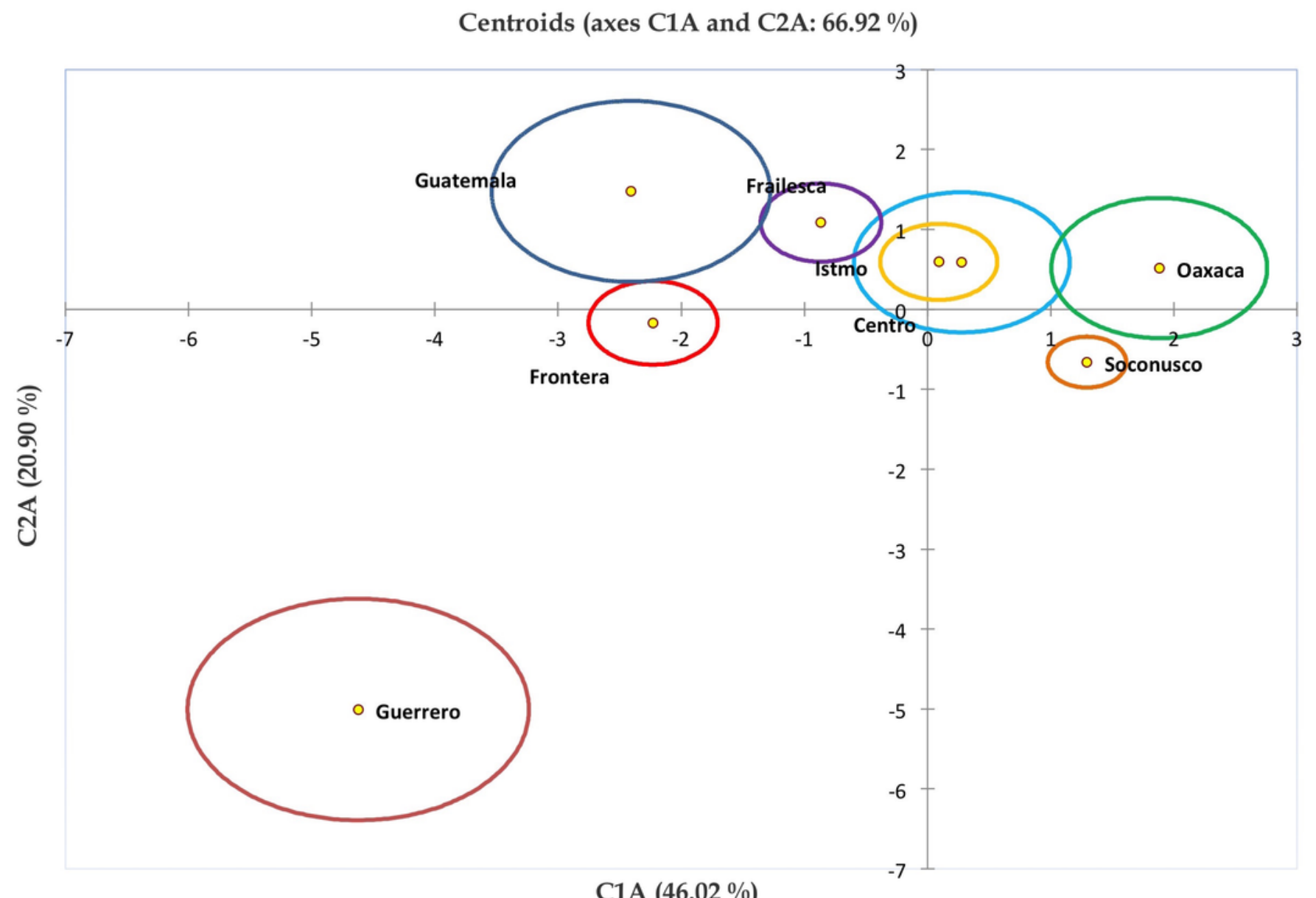




\section{5}

Discriminant analysis of Jatropha curcas landraces from Meso-America base on floral traits.

Grouping by populations of 90 accessiones of Jatropha curcas L. from Chiapas state, from the Jatropha Germplasm Bank of the Autonomous University of Chiapas. Traits: Male flower diameter, Male sepal lenght, Male sepal width, Male petal lenght, Male petal width, Male nectary length, Male nectary thickness, Filament lenght, Filament thickness, Anther lenght, Anther thickness, Pollen diameter, Trichomes in male flowers, Female/hermaphrodite flower diameter, Female/hermaphrodite sepal length, Female/hermaphrodite sepal width, Female/hermaphrodite petal length, Female/hermaphrodite petale width, Female/hermaphrodite nectary length Female/hermaphrodite nectary thickness, Pistil lenght, Pistil thickness, Ovary lenght, Ovary thickness, Ovule lenght, Ovule thickness, Trichomes in female/hermaphrodite flowers. 


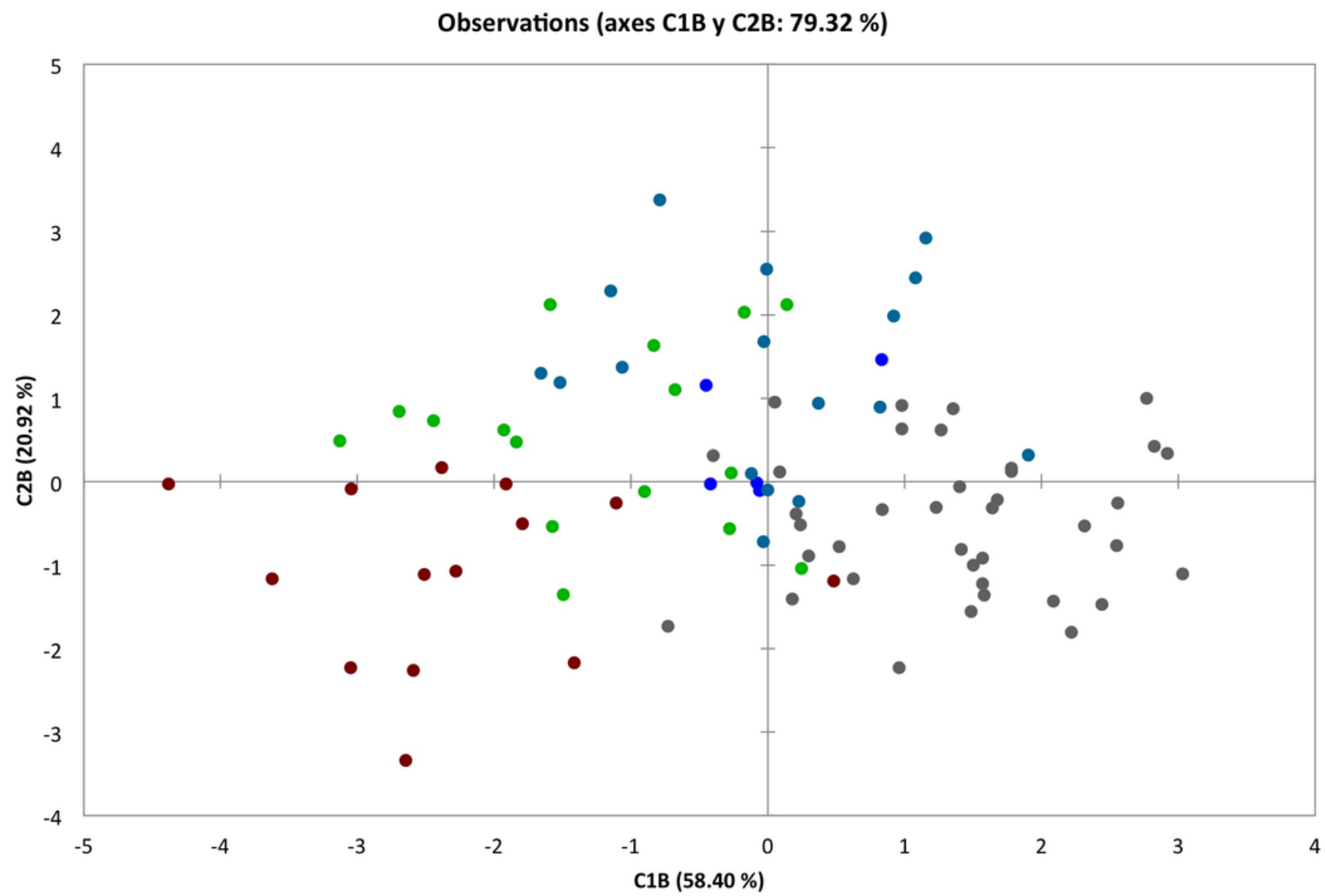

- Centro - Frailesca - Frontera Istmo - Soconusco 


\section{6}

Biplot of discriminant scores based on discriminant functions 1 and 2 .

Chart of centroids of five populations of Jatropha curcas L. Chiapas state, from the Jatropha Germplasm Bank of the Autonomous University of Chiapas. Traits: Male flower diameter, Male sepal lenght, Male sepal width, Male petal lenght, Male petal width, Male nectary length, Male nectary thickness, Filament lenght, Filament thickness, Anther lenght, Anther thickness, Pollen diameter, Trichomes in male flowers, Female/hermaphrodite flower diameter, Female/hermaphrodite sepal length, Female/hermaphrodite sepal width, Female/hermaphrodite petal length, Female/hermaphrodite petale width, Female/hermaphrodite nectary length Female/hermaphrodite nectary thickness, Pistil lenght, Pistil thickness, Ovary lenght, Ovary thickness, Ovule lenght, Ovule thickness, Trichomes in female/hermaphrodite flowers. 
Centroids (axes C1B and C2B: 79.32 \%)

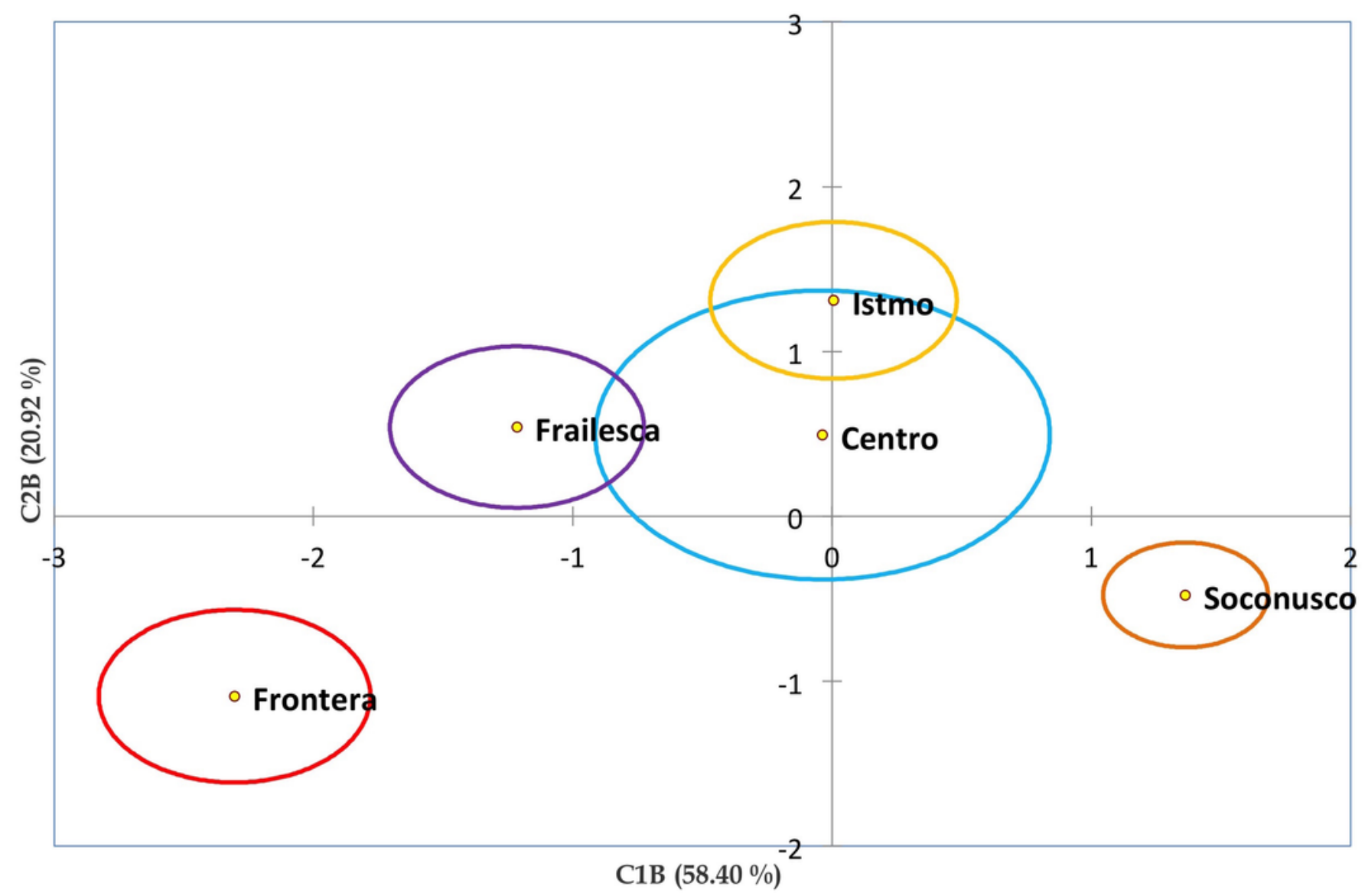




\section{7}

Clustering of Jatropha curcas accessions collected in Meso-America.

Dissimilarity dendrogram of 103 accessions of Jatropha curcas L. in southern México, from the Jatropha Germplasm Bank of the Autonomous University of Chiapas. Colors of branches denote groups formed. Traits: Male flower diameter, Male sepal lenght, Male sepal width, Male petal lenght, Male petal width, Male nectary length, Male nectary thickness, Filament lenght, Filament thickness, Anther lenght, Anther thickness, Pollen diameter, Trichomes in male flowers, Female/hermaphrodite flower diameter, Female/hermaphrodite sepal length, Female/hermaphrodite sepal width, Female/hermaphrodite petal length, Female/hermaphrodite petale width, Female/hermaphrodite nectary length Female/hermaphrodite nectary thickness, Pistil lenght, Pistil thickness, Ovary lenght, Ovary thickness, Ovule lenght, Ovule thickness, Trichomes in female/hermaphrodite flowers. For details of grouping mode see the Materials an Methods section. 


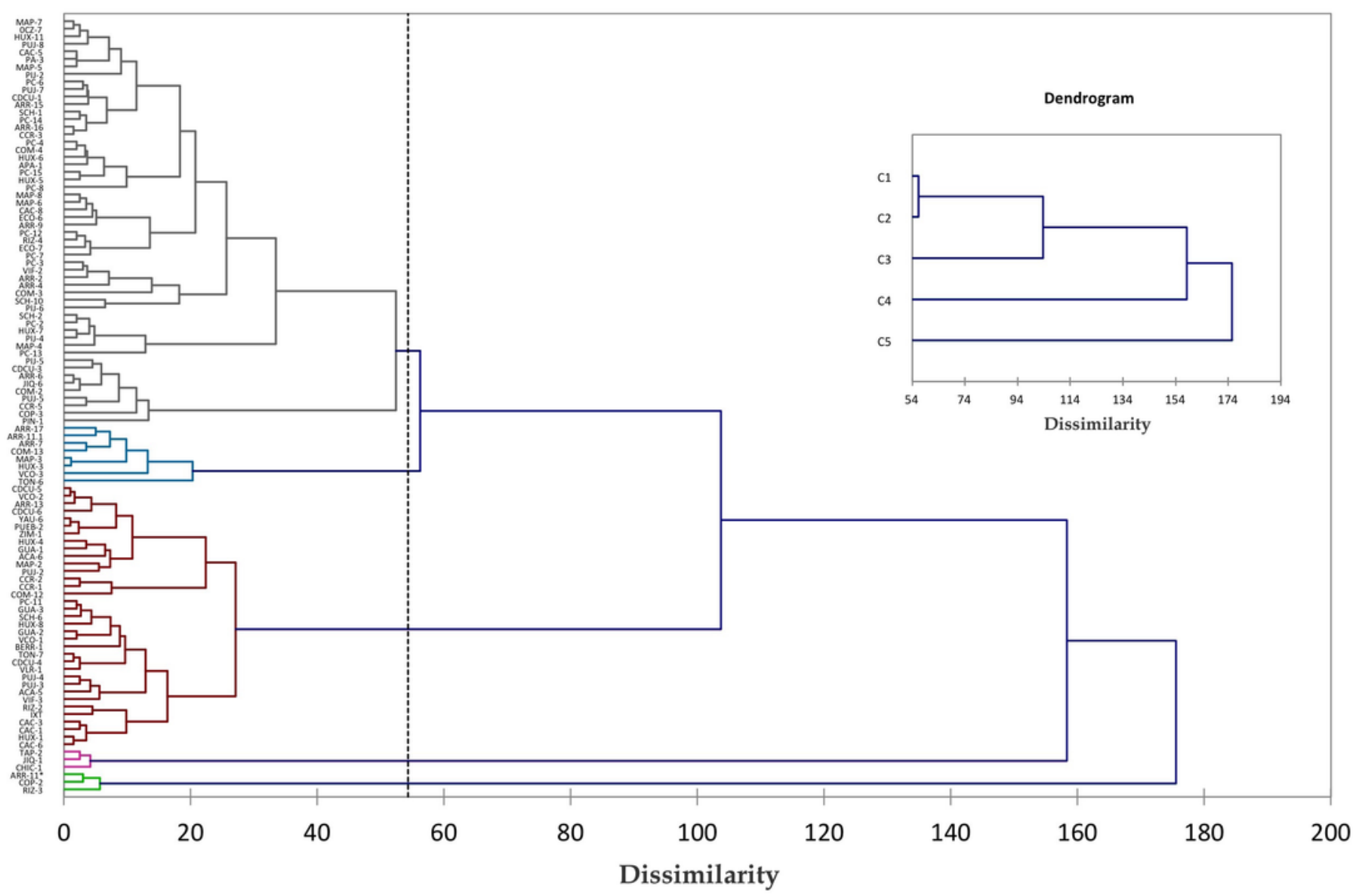




\section{8}

Clustering of Jatropha curcas accessions collected in the State of Chiapas, Mexico.

Dissimilarity dendrogram of 90 accessions of Jatropha curcas L. of Chiapas state, from the Jatropha Germplasm Bank of the Autonomous University of Chiapas. Colors of branches denote groups formed. Traits: Male flower diameter, Male sepal lenght, Male sepal width, Male petal lenght, Male petal width, Male nectary length, Male nectary thickness, Filament lenght, Filament thickness, Anther lenght, Anther thickness, Pollen diameter, Trichomes in male flowers, Female/hermaphrodite flower diameter, Female/hermaphrodite sepal length, Female/hermaphrodite sepal width, Female/hermaphrodite petal length, Female/hermaphrodite petale width, Female/hermaphrodite nectary length Female/hermaphrodite nectary thickness, Pistil lenght, Pistil thickness, Ovary lenght, Ovary thickness, Ovule lenght, Ovule thickness, Trichomes in female/hermaphrodite flowers. For details of grouping mode see the Materials an Methods section. 


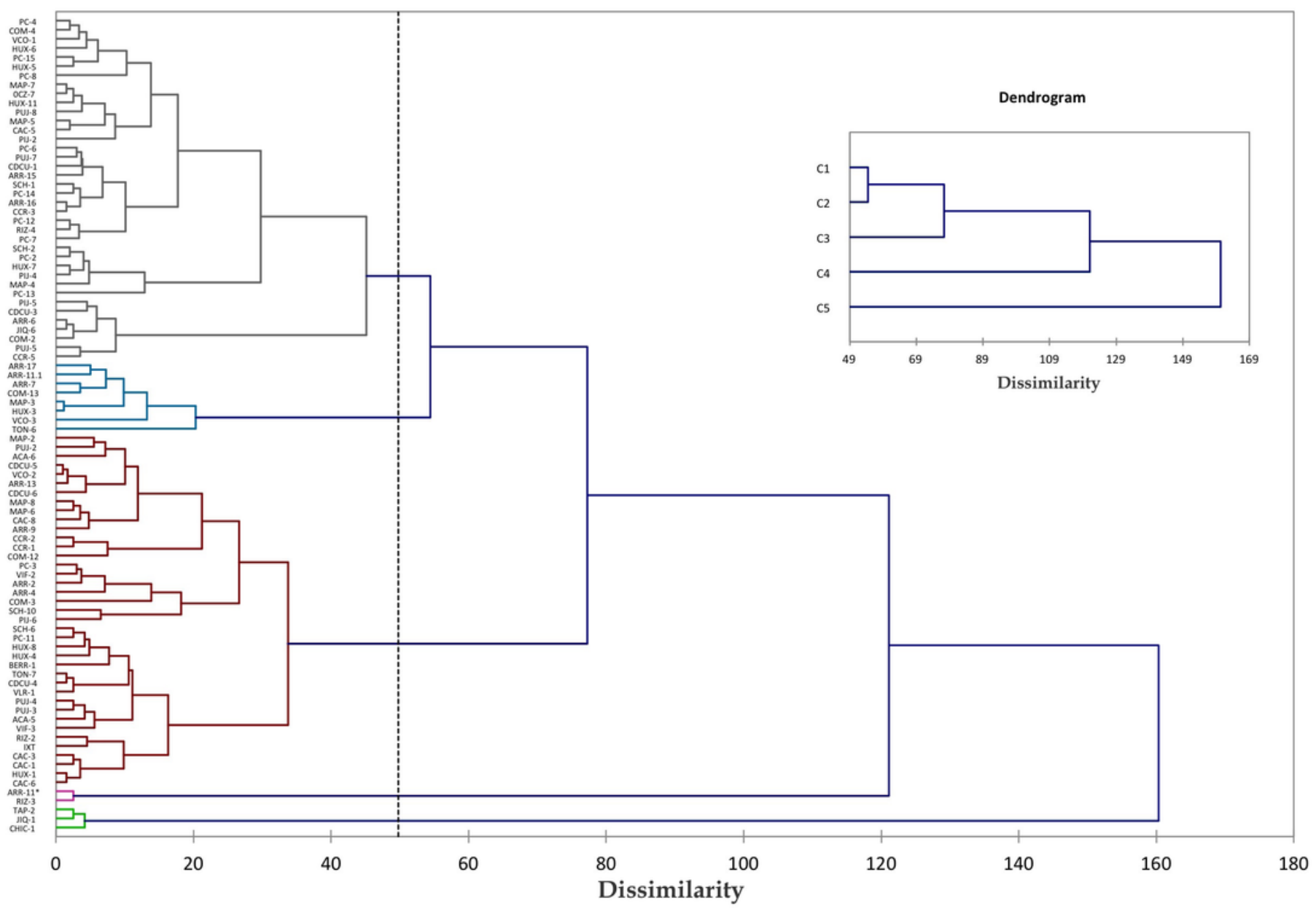




\section{Table $\mathbf{1}$ (on next page)}

Sexuality of Jatropha curcas landraces collected in Meso-America.

Classification of 103 accessions of Jatropha curcas L. from the Jatropha Germplasm Bank of the Universidad Autónoma de Chiapas, based on their sexual descriptors. 
1

\begin{tabular}{|c|c|c|}
\hline Type of plant & Accessions (n) & Description \\
\hline Monoecious & 95 & $\begin{array}{l}\text { Plants with male and females flowers in the } \\
\text { same inflorescence }\end{array}$ \\
\hline \multicolumn{3}{|l|}{ Dioecious } \\
\hline Gynoecious & 3 & Plants with only female flowers \\
\hline Androecious & 2 & Plants with only male flowers \\
\hline \multicolumn{3}{|l|}{ Hermaphrodites } \\
\hline Andromonoecious & 1 & Plants with male and hermaphrodite flowers \\
\hline Androgynomonoecious & 2 & $\begin{array}{l}\text { Plants that has mostly male flowers, with a } \\
\text { few female and hermaphrodite flowers }\end{array}$ \\
\hline
\end{tabular}

2

3

4

5 
Table 2 (on next page)

Discriminant analysis of flower traits of Jatropha curcas collected in Meso-America.

Eigenvalues of the five main components, based on floral characters of 103 accessions of Jatropha curcas L. in southern Mexico. 
1

\begin{tabular}{cccc}
\hline Component & Eigenvalues & Variance (\%) & $\begin{array}{c}\text { Cumulative } \\
\text { Variance\% }\end{array}$ \\
\hline 1 & 2.430 & 46.018 & 46.018 \\
2 & 1.104 & 20.898 & 66.916 \\
3 & 0.720 & 13.642 & 80.558 \\
4 & 0.445 & 8.424 & 88.982 \\
5 & 0.264 & 5.001 & 93.983 \\
\hline
\end{tabular}

2

3

4

5

6

7

8

9

10

11

12

13

14

15 


\section{Table 3(on next page)}

Discriminant analysis of flower traits of Jatropha curcas from Meso-America.

Eigenvalues of the four principal components, based on floral characters of 90 accessions of Jatropha curcas L. in the State of Chiapas, Mexico. 
1

\begin{tabular}{cccc}
\hline Component & Eigenvalues & Variance (\%) & $\begin{array}{c}\text { Cumulative } \\
\text { variance (\%) }\end{array}$ \\
\hline 1 & 1.984 & 58.40 & 58.40 \\
2 & 0.711 & 20.92 & 79.320 \\
3 & 0.571 & 16.81 & 96.14 \\
4 & 0.131 & 3.87 & 100 \\
\hline
\end{tabular}

2

3

4 